cross-section, and the computer can easily calculate its visual acuity - that is, spatial resolution - as a single real number. It would be much harder to come up with an equivalent numerical expression of the quality of a cheetah's leg or backbone. Nilsson and Pelger began with a flat retina, atop a flat pigment layer and surmounted by a flat, protective transparent layer (see figure). The transparent layer was allowed localized random mutations of its refractive index. They then let the model deform itself at random, constrained only by the requirement that any change must be only $1 \%$ bigger or smaller than what went before. And, of course, in order for a change to be accepted, it had to be an improvement on what went before.

The results were swift and decisive. A trajectory of steadily improving acuity led unhesitatingly from the flat beginning through a shallow cup to a steadily deepening cup. The transparent layer thickened to fill the cup and smoothly curved its outer surface. And then, almost like a conjuring trick, a portion of this transparent filling condensed into a local, spherical subregion of higher refractive index - not uniformly higher, but a gradient of refractive index such that the spherical region functioned as an excellent graded-index lens. Best of all, the ratio of the focal length of the lens to its diameter settled down at a close approximation to Mattiessen's ratio, long known to be the ideal value for a graded-index lens.

Turning to the question of how long the evolution might have taken, Nilsson and Pelger had to make some plausible population-genetic assumptions. They chose values of heritability, coefficient of variation and intensity of selection from published observations from the field. Their guiding principle in choosing such numbers was pessimism. For each assumption they made, they wanted to err in the direction of overestimating the time taken for the eye to evolve. They even went so far as to assume that any new generation differed in only one part of the eye: simultaneous changes in different parts of the eye, which would have speeded up evolution, were banned. But even with these conservative assumptions, the time taken to evolve a fish eye from flat skin was under 400,000 generations. Assuming typical generation times of one year for small animals, the time needed for the evolution of the eye, far from stretching credulity with its vastness, turns out to be too short for geologists to measure. It is a geological blink.

Richard Dawkins is in the Department of Zoology, University of Oxford, South Parks Road, Oxford OX1 3PS, UK.

1. Dawkins, R. The Blind Watchmaker (Penguin, London Norton, New York, 1986)

2. Nitsson, D.-E. \& Pelger, S. Proc. R. Soc. B256, 53-58 (1994).

3. Salvini-Plawen, L.v. \& Mayr, E. in Evolutionary Biology Vol. 10 (eds Hecth, M. K., Steere, W. C. \& Wallace, B. 207-263 (Plenum, New York, 1977).

4. Land, M. F. in Handbook of Sensory Physiology (ed. Autrum, H.) 471-592 (Springer. Berlin. 1980)

\title{
Fragments of history preserved
}

АвоUт 85 per cent of the meteorites observed to fall on the Earth are chondrites. Except for volatile elements such as hydrogen, helium and nitrogen, chondrites have elemental abundances similar to those of the Sun's photosphere; these meteorites preserve the bulk chemistry of the earliest solids to form in the cloud of gas and dust known as the solar nebula. Chondrites that were not greatly altered in their parent asteroids (by water, heat or shock) have heterogeneous mineral compositions and preserve the textures they inherited from the nebula, and typically contain submillimetre igneous spherules with solar compositions (known as chondrules), fine-grained dust of similar constitution, and grains of metallic ironnickel and sulphide. Carbonaceous chondrites also contain abundant refractory inclusions (also known as $\mathrm{Ca}$, Al-rich inclusions or CAls), some of which have isotope anomalies suggesting the presence of pre-solar solids.

Chondrules are believed to have formed from clumps of precursor dust by transient heating events. Analyses of chondrule bulk compositions ${ }^{1}$ suggest that several chemically discrete components were involved; one was rich in refractory lithophile elements and may have been derived from CAls. The CAls themselves also probably formed by high-temperature processes, some from evaporative residues, others by conden. sation. The relationship between chondrules and CAls is a long-standing puzzle: there are compound chondrules (made up of two chondrules stuck together) and there are compound CAls, but until now there have been no known compound chondrule-CAl objects.

That is why the above chondrule from the Allende meteorite, described on page 723 of this issue ${ }^{2}$ and pictured here about 40 times lifesize, is so important. For the first time we have a chondrule containing a relict (unmelted) precursor grain that appears to be a CAl fragment. The 200 $\mu \mathrm{m}$ grain is spinel $\left(\mathrm{MgAl}_{2} \mathrm{O}_{4}\right)$ containing several refractory silicate inclusions (in. cluding Al- and Ti-rich pyroxene) and platinum-group metal nuggets; all of group metal nuggets; all of these phases have compositions within the ranges of those in CAls in other carbonaceous chondrites.

Although $\mathrm{Ca}, \mathrm{Al}-$ rich chondrules have been described before ${ }^{3}$, including some pos. sessing fractionated rareearth-element patterns similar to those in CAls ${ }^{4,5}$, these objects preserve only the chemical signatures of their CAI precursors. The chondrule described by Misawa and Fujita ${ }^{2}$ preserves part of the CAl itself.

Taken to a plausible extreme, the evidence suggests that after CAls formed in the nebula, some were broken by collisions and entrained in nebular dust chondrule formation. Flashheating of such clumps produced chondrules; dust clumps containing a high mass fraction of CAl fragments formed $\mathrm{Ca}$, Al-rich chondrules. In the present case, the heating event was mild enough that part of the CAI survived.

Alan E. Rubin

Alan E. Rubin is at the Institute of Geophysics and Planetary Physics, University of California, Los Angeles, California 90024, USA.

1. Grossman, J. N. \& Wasson, J. T. Geochim. cosmochim. Acta 46, 1081-1099 (1982)

. Misawa, K. \& Fujita, T. Nature 368, 723-726 (1994).

3. Misawa, K. \& Fujita, T. Nature 368, 723-726 (1994).

4. Rubin, A. E. \& Wasson, J. T. Geochim. cosmochim. Acta 51, 1923-1937 (1987).

Misawa, K. \& Nakamura, N. Nature 334, 47-50 (1988) 